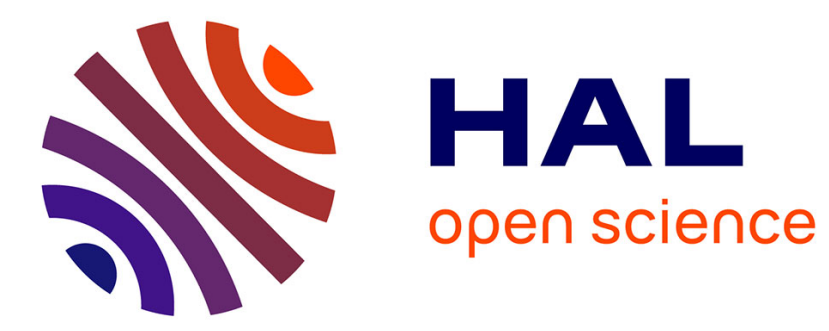

\title{
Mechanical Stabilisation for Bainitic Reaction in a Fe-Mn-Si-C Bainitic Steel
}

\author{
J. Yang, C. Huang, W. Hsieh, C. Chiou
}

\section{To cite this version:}

J. Yang, C. Huang, W. Hsieh, C. Chiou. Mechanical Stabilisation for Bainitic Reaction in a FeMn-Si-C Bainitic Steel. Journal de Physique IV Proceedings, 1995, 05 (C8), pp.C8-497-C8-502. 10.1051/jp4:1995876 . jpa-00254125

\section{HAL Id: jpa-00254125 https://hal.science/jpa-00254125}

Submitted on 1 Jan 1995

HAL is a multi-disciplinary open access archive for the deposit and dissemination of scientific research documents, whether they are published or not. The documents may come from teaching and research institutions in France or abroad, or from public or private research centers.
L'archive ouverte pluridisciplinaire HAL, est destinée au dépôt et à la diffusion de documents scientifiques de niveau recherche, publiés ou non, émanant des établissements d'enseignement et de recherche français ou étrangers, des laboratoires publics ou privés. 


\title{
Mechanical Stabilisation for Bainitic Reaction in a Fe-Mn-Si-C Bainitic Steel
}

\author{
J.R. Yang, C.Y. Huang, W.H. Hsieh and C.S. Chiou* \\ Institute of Materials Science and Engineering, National Taiwan University, 1 Roosevelt Rd. Sec. 4, \\ Taipei, Taiwan, Republic of China \\ * Department of Mechanical Engineering, Yuan-Ze Institute of Technology, 135 Far-East Rd. Chung-Li, \\ Taiwan, Republic of China
}

\begin{abstract}
In this work, the effects of different amounts $(5,10,20,40 \%)$ of compressive deformation of austenite on the isothermal transformation of bainite in a Fe-Mn-Si-C alloy steel have been investigated. It is found that the prior deformation of austenite retards significantly the bainitic transformation. At the same isothermal transformation temperature, as the amount of prior deformation is higher, the quantity of bainite (which can be obtained after the isothermal transformation is completed) becomes less and it is also more difficult to develop the classical sheaf-like structure. The evidence implies that severe deformation causes mechanical stabilisation of austenite for bainitic transformation.
\end{abstract}

\section{Introduction}

The effect of stress on bainite transformation in alloy steels has been the object of much investigation [1-5]. As the bainite transformation is with an invariant-plane strain shape deformation [6], the response of bainitic transformation to stress is expected to be essentially similar to that of martensitic transformation. Recent research $[3,4]$ has clearly shown that the external tensile stress below the yield strength of the austenite accelerates the bainite transformation and favours the development of certain crystallographic variants of bainite [4]. The extent of transformation to bainite at any temperature is restricted by the incomplete reaction phenomenon [6], but the application of an elastic stress during transformation has been reported to cause an increase in the degree of reaction.[7]

When the applied stress exceeds the yield strength of the austenite, plastic deformation is generally presumed to promote the overall rate of the bainite reaction $[1,8]$. However, Davenport used hot rolled samples, which have demonstrated [9] that the austenite which is deformed to a larger extent, tends to transform to bainite at a lower temperature during continuous cooling. This could be interpreted as mechanical stabilisation of the austenite [10] because the alloy used had sufficient hardenablity to obtaine bainite, without interference from any of the addition diffusional reactions. It has been well estabilished for martensitic transformation that severe deformation causes mechanical stabilisation of the austenite [11]. This effect appears to result from an increase in difficulty of plate propagation into the austenite phase due to work hardening of the austenite.

The purpose of the present work is to explore whether the mechanical stabilisation of the austenite occurs during the isothermal transformation of bainite in a steel containing a rather large concentration of silicon, which retards the formation of cementite. 


\section{Experimental Procedure}

The experimental steel was made as $20 \mathrm{~kg}$ vacuum induction melts using high purity base materials. The ingot was forged and hot rolled into $10 \mathrm{~mm}$ diameter rods, followed by a hot-swage reduction into $3.2 \mathrm{~mm}$ diameter rods. The rods were sealed in quartz capsules (under a partials pressure of argon) and homogenised at $1200^{\circ} \mathrm{C}$ for three days. The chemical composition of the steel consisted of Fe- $0.43 \mathrm{C}$ $3.0 \mathrm{Mn}-2.02 \mathrm{Si}(\mathrm{wt} \%)$. In this work, all the thermal and thermo-mechanical treatments have been carried out in a Dilatronic III RDP deformation dilatometer of Theta Industries, Inc. The dilatometer has been interfaced a computer work station PDP 11/55 central processor for analysing the resulting data.The software package (provide by Theta Industies, Inc) can give a flexible and complete environment to execute the deformation and isothermal transformation experiments. The length, time and temperature information can be recorded in microsecond intervals, and the level of vacuum can reach $10^{-5}$ torr to protect specimens from oxidation. The dilatometer specimens were prepared from the homogenised rods in the form of $3 \mathrm{~mm}$ diameter cylindrical rods with $6 \mathrm{~mm}$ length.

The scheme of the main thermo-mechanical process performed in the dilatometer is given in Fig.1. After reautenitisation at $950^{\circ} \mathrm{C}$ for $10 \mathrm{~min}$, the samples were cooled downed to $750^{\circ} \mathrm{C}$ at cooling rate $60^{\circ} \mathrm{C} / \mathrm{s}$, immediately, different amounts $(5,10,20$ and $40 \%)$ of compressive deformation were executed at $750^{\circ} \mathrm{C}$ within $3 \mathrm{~s}$, and then the deformed specimens were rapidly cooled to different temperatures (ranging from 350 to $410^{\circ} \mathrm{C}$ ) for isothermal transformations of bainite. After the isothermal transformations were completed, the samples were quenched at cooling rate $200^{\circ} \mathrm{C} / \mathrm{s}$ to the ambient temperature. The thermal treatments for undeformed specimens were identical to those of Fig. 1 without deformation being applied at the temperature $750^{\circ} \mathrm{C}$.

The specimens for optical metallography were prepared from dilatometer specimens. The observed section was along to the direction of compression. The specimens were mechanically polished and then etched in $2 \%$ nital solution. The measuremens of volume fractions of bainite were conducted on a scanning electron microscope at a magnification of $400 x$. For each specimen 30 frames were measured with a grid of 400 counting points. The standard deviation of the measurements was within $0.5 \%$.

Transmission electron microscopy specimens were prepared from $0.25 \mathrm{~mm}$ thick discs slit from dilatometer specimens. For the deformed samples, the observed section was perpendicular to the direction of compression. The discs were thinned to $0.05 \mathrm{~mm}$ by abrasion on silicon carbide papers and then singlejet electropolished using a mixture of $5 \%$ perchloric acid, $25 \%$ glycerol and $70 \%$ ethanol at the ambient temperature and $60 \mathrm{~V}$ polishing potential. They were examined using a JEOL 100CX transmission electron microscopy operating at $100 \mathrm{kV}$.

\section{Results and Discussion}

Figs 2 - 5 shows the optical microstructures obtained from the dilatometer specimens (without and with 10 and $40 \%$ compressive deformations separately) after completion of isothermal transformations at different temperatures ranging from 410 to $350^{\circ} \mathrm{C}$. The classical sheaf-like bainitic structure can be obtained in the undeformed specimens (Figs 2(a), 3(a), 4(a) and 5(a)) for different isothermal temperatures. This morphology results from a series of parallel platelets emanating from the prior austenite grain boundaries (Fig. 6(a)). The volume fraction of sheaf-like bainitic structure increases with decreasing the isothermal temperature. At the same isothermal temperature, as the amount of deformations is higher, the parallel formations of plates are more difficult to develop and the quantities of bainite (the transformation product) also become less. The optical metallographs (Figs 2(c), 3(c), 4(c) and 5(c)) obtained from the samples with a $40 \%$ compressive deformation display that the structures are very fine and the majority of ferrite plates appear as tiny scattered islands which apparently outline the deformation bands. Fig. 6(b) presents the transmission electron micrograph for the corresponding optical metallograph shown in Fig. 5(c). It shows that the ferrite plates can not be neatly arranged into packets and that the microstructure becomes rather chaotic. The result implies that severe deformation causes the difficulty of bainitic ferrite plate propagation into the austenite.

The isothermal dilatometric curves for bainitic transformation (at different isothermal temperatures) obtained from the samples with different amounts of deformation are displayed in Fig. 7. Fig. 7(a) shows that at the isothermal temperature $410^{\circ} \mathrm{C}$ the maximum degree of transformation decreases with increasing the amount of compressive deformation. The rate of austenite to bainite transformation decreases, and the incubation time increases, with increasing the amount of deformation. The kinetics of bainite formation become slower at the higher amount of prior deformation. Fig. 7(b)also shows the same trend for 
isothermal transformation at $350^{\circ} \mathrm{C}$. The volume fractions of bainite (after the isothermal reaction of bainite stops) have been measured from the scanning electron micrographs. For different isothermal temperatures the volume fraction of bainite versus the amount of deformation is plotted in Fig.8. It shows that at the same isothermal temperature, the higher amounts of deformation, the less quantities of bainite can be obtained. This tendency become stronger at the lower isothermal temperature. The results suggest that severe deformation leads to mechanical stabilisation of the austenite against subsequent isothermal transformation of bainite.

\section{Conclusions}

It has been found that the prior deformation of austenite retards significantly the bainitic transformation. At the same isothermal temperature, the volume fraction of bainite (after the isothermal transformation of bainite ceases) decreases with increasing the amount of deformation. The overall bainitic transformation kinetics become slower at the higher amount of prior deformation. The applied compressive deformation hinders the development of classical sheaf-like structure. The evidence suggests that severe deformation leads to mechanical stabilisation of the austenite and causes the difficulty of bainitic ferrite plate propagation into the austenite.

\section{Reference}

[1] Freiwillig R., Kudrman J.and Chraska P., Met. Trans. 7A(1976)1091.

[2] Porter L.F.and Rosenthal P.C., Acta Metall. 7(1995)504.

[3] Umemoto M., Bando S. and Tamura I., in "proceedings of the international conference on martensitic transformations", Tokyo, The Japan Institute of Metals, 1986, P. 595.

[4] Bhadeshia H.K.D.H., David S.A., Vitek J.M.and Reed R.W., Mater. Sci. Technol. 7(1991)686.

[5] Bhadeshia H.K.D.H., "Bainite in Steels" (THe Institute of Materials, London, 1992) P.210.

[6] Bhadeshia H.K.D.H.and Christian J.W., Metall. Trans. 21A(1990)767.

[7] Cottrell A.H., J. Iron Steel Inst. 151(1945)93.

[8] Duckworth W.E., J. Met. 18(1966)915.

[9] Davenport A.T., in "The Hot Deformation of Austenite" (ed. J.B. Ballance )TMS-AIME, NY, 1977, pp. 517-536.

[10] Tsuzaki K., Ueda T., Fujiwara K.and Maki T., in "New Materials and Processes for the Future", Proc. 1st JapanInt SAMPE Symp. and Exhib., Soc. for Advancement of Mater. and Process Eng., Chiba, Japan, 1989, pp. 699-704.

[11] Bhadeshia H.K.D.H., "Bainite in Steels" (THe Institute of Materials, London, 1992) P.219.

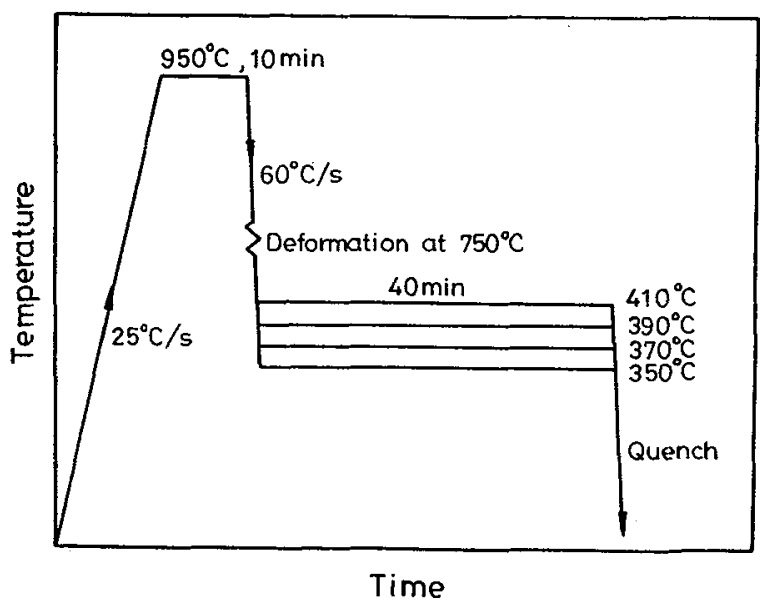

Fig. 1 Schematic diagram showing the main thermo-mechanical processes performed in the dilatometer. 


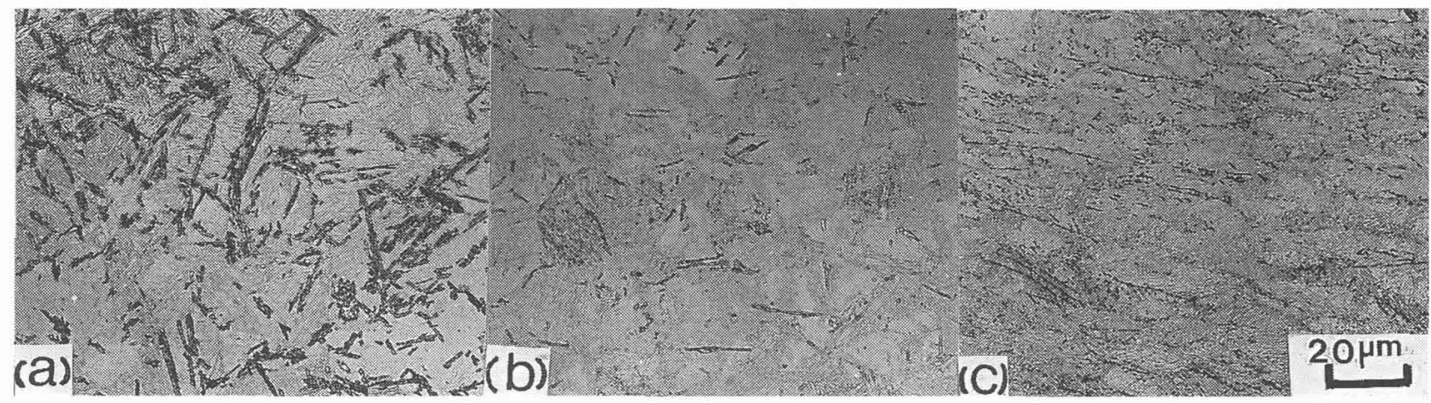

Fig. 2 Optical metallographs showing the microstructures obtained from the dilatometric specimens isothermally treated at $410{ }^{\circ} \mathrm{C}$ for 30 min with different amounts of prior deformation: (a) $0 \%$, (b) $10 \%$ and (c) $40 \%$.

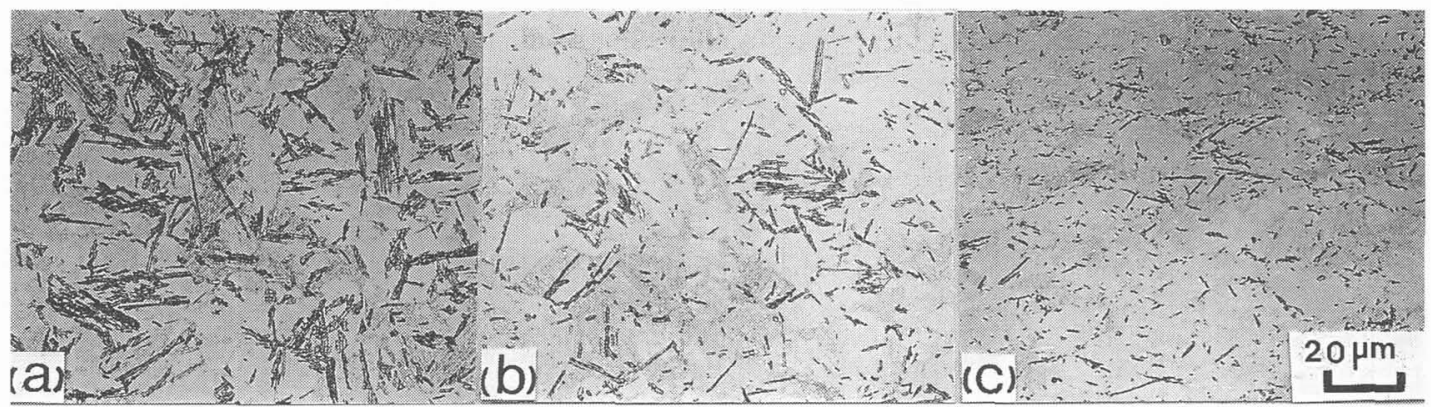

Fig. 3 Optical metallographs showing the microstructures obtained from the dilatometric specimens isothermally treated at $390^{\circ} \mathrm{C}$ for $30 \mathrm{~min}$ with different amounts of prior deformation: (a) $0 \%$, (b) $10 \%$ and (c) $40 \%$.

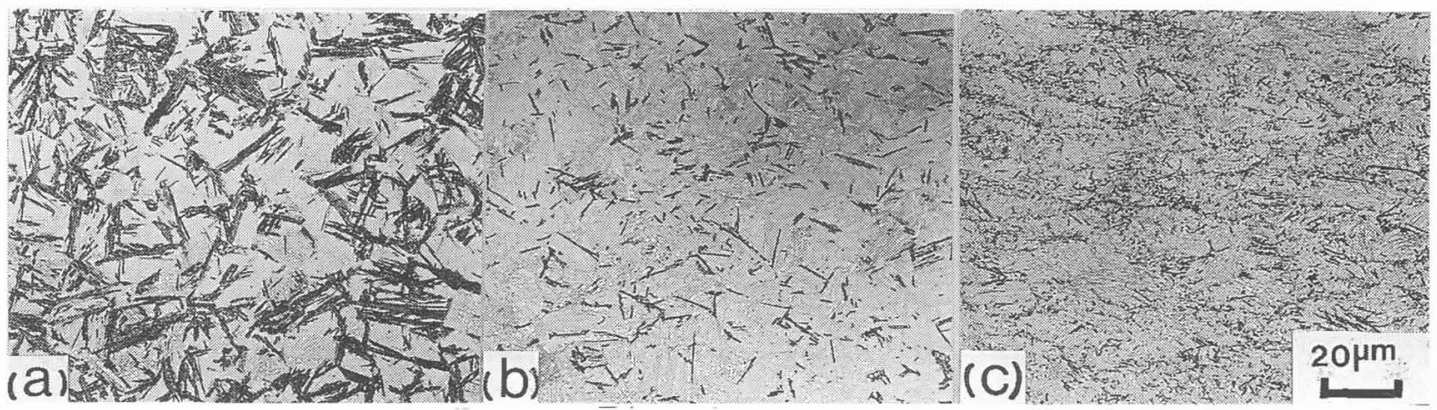

Fig. 4 Optical metallographs showing the microstructures obtained from the dilatometric specimens isothermally treated at $370^{\circ} \mathrm{C}$ for 30 min with different amounts of prior deformation: (a) $0 \%$, (b) $10 \%$ and (c) $40 \%$.

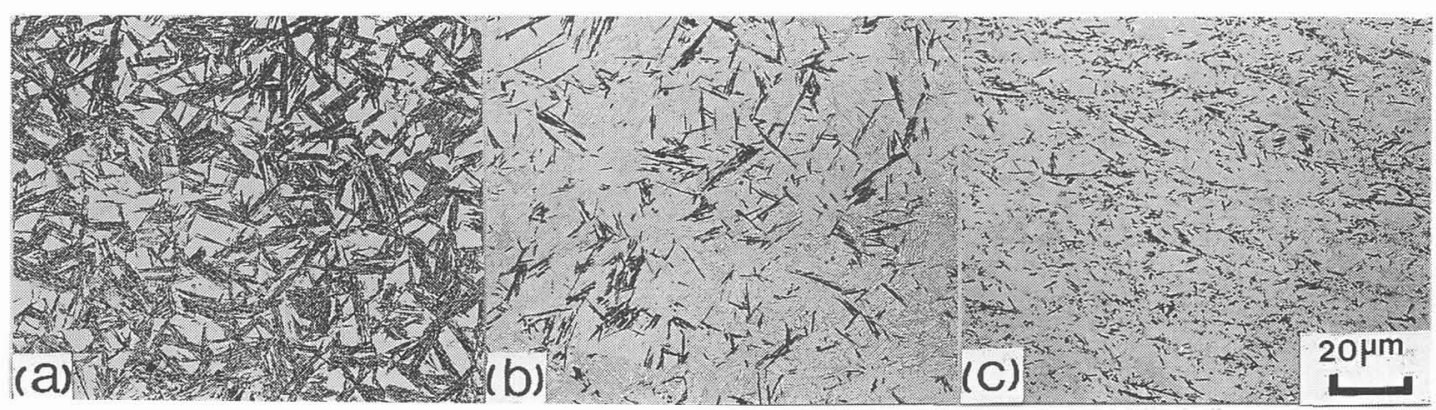

Fig. 5 Optical metallographs showing the microstivetures obtaincd from the dilatometric specimens isothermally treated at $350^{\circ} \mathrm{C}$ for $30 \mathrm{~min}$ with different amounts of prior deformation: (a) $0 \%$, (b) $10 \%$ and (c) $40 \%$. 
C8-501

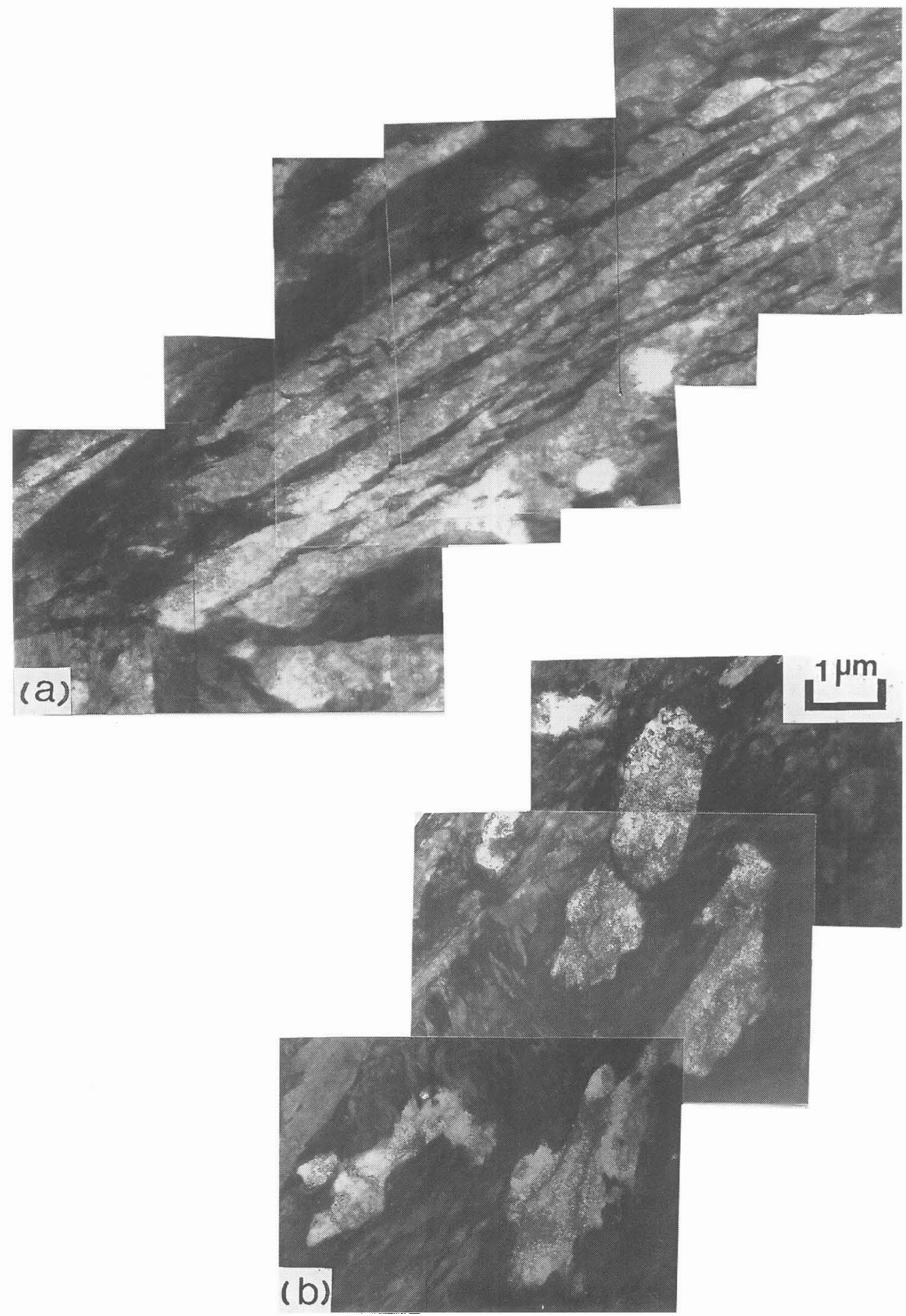

Fig. 6 Transmission electron micrographs (a) and (b) showing the microstructures for corresponding optical metallographs of Figs. 5(a) and 5(c) respectively. 

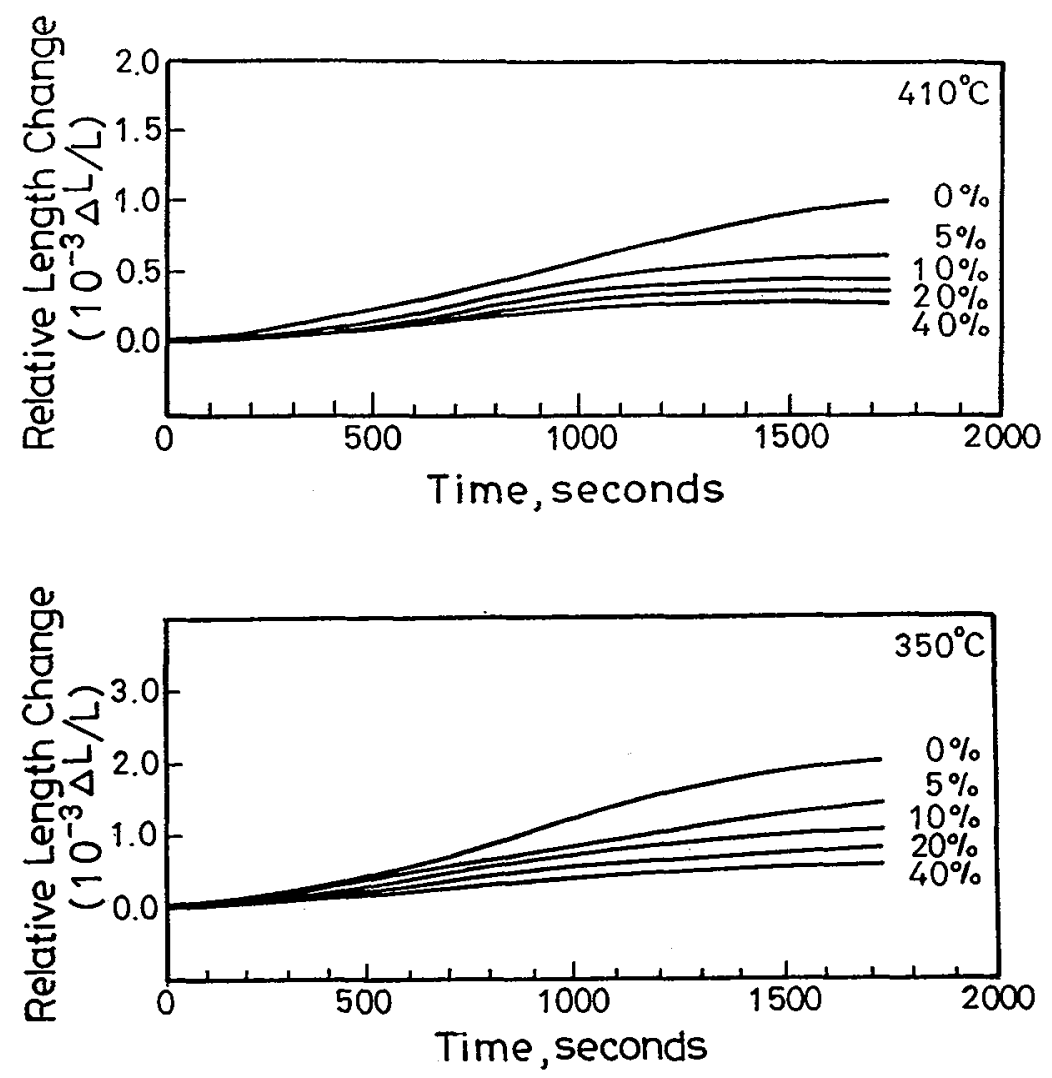

Fig. 7 Dilatometric curves for isothermal transformation at (a) $410^{\circ} \mathrm{C}$ and (b) $350^{\circ} \mathrm{C}$ with and without prior deformation (the amounts of prior deformation indicated).

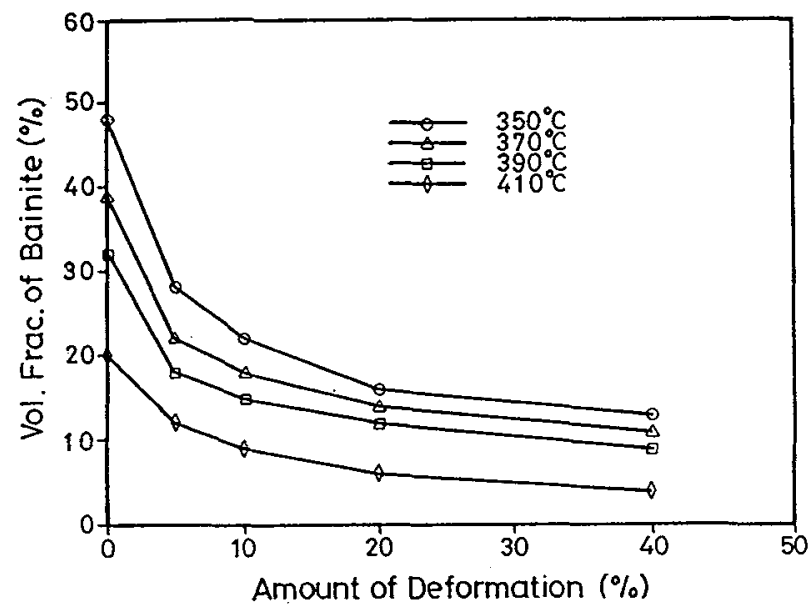

Fig. 8 Plot of the volume fraction of bainite versus the amount of prior deformation for different isothermal temperatures. The volume fractions of bainite were obtained after the reactions of bainite had been complete. 